\title{
Escola do campo multisseriada: experiência docente
} baseado na experiência docente e revisão literária, com o objetivo de fazer uma prospecção preliminar da realidade no município de Santa Maria/RS. Em função da constante redução dos discentes do campo, a implantação das classes multisseriadas torna-se periodicamente uma necessidade local, experienciada na maioria das atuais nove instituições do meio rural, as quais representam $20 \%$ do total de Escolas de Ensino Fundamental do município. Logo, formação continuada dos professores, novas metodologias de ensino, adequação do conteúdo à realidade do campo, entre outros, são desafios a serem enfrentados para um ensino mais eficaz e inovador. A temática, por ser um objeto de investigação inexplorado localmente, necessita estudos complementares, como este, que integra reflexões sobre o ensino multisseriado.

\section{Multiseriate rural schools: teaching experience}

\begin{abstract}
This study is a survey of issues concerning to the multiseriate Rural Education based on teaching experience and literature review, in order to make a preliminary prospection of the reality in the municipal district of Santa Maria / RS. Due to reduction constant of the rural students, the implementation of multigrade schools periodically became a local need, reality of most current 9 schools that represent $20 \%$ of total Elementary Schools. Continuing teachers training, new education methodologies; adequation of the contents at rural reality, among others, are challenges to be faced for a teaching more effective and innovative. The thematic, as a subject of investigation untapped locally, it needs further studies.
\end{abstract}

Franciele Druzian*

Ane Carine Meurer**

*Pedagoga Especialista em Alfabetização e Letramento e Professora da Escola Municipal de Ensino Fundamental Major Tancredo Penna de Moraes.

**Professora Doutora do Departamento de Fundamentos da Educação do Centro de Educação/CE e do Programa de Pós-Graduação em Geografia e Geociências da Universidade Federal de Santa Maria PPGGeo/UFSM.

\section{Palavras-chave:}

Classes multisseriadas;

Educação do Campo;

Ensino Fundamental.

Key-Words:

Multiseriated Classes; Rural

Education; Elementary

Education Practice

Teaching.
Geografia Ensino \& Pesquisa, vol. 17, n. 2, maio./ago. 2013 


\section{Introdução}

Uma das consequências da Revolução Industrial no Brasil foi o grande êxodo rural, o qual também teve influências no crescimento e relativo desenvolvimento dos meios urbanos a fim de fornecer suporte e bem estar à população, deixando o desenvolvimento do campo em segundo plano, sem ser diferente com a educação (ROTTA e ONOFRE, 2010).

Discutir preceitos e formação da educação do campo constitui-se como uma preocupação em busca da democratização do ensino, direito esse garantido pela Constituição Federal (MACHADO e KNORST, 2010). Mesmo que o cenário, a partir de 2000, tenha apresentado avanços das políticas educacionais e das lutas dos movimentos sociais realizadas em prol da educação do campo, de uma forma geral, ainda há muito que se debater e melhorar (CAVALCANTE, 2010).

A educação deve estabelecer paradigmas que busquem se atualizar constantemente de forma a promover os valores e ideais de uma sociedade mutante. $\mathrm{O}$ fato de a educação rural apresentar sérias lacunas em sua formação e em sua efetividade surte, como reflexo, a falta de perspectiva do agricultor familiar que não consegue, por falta de recursos, acompanhar o processo de evolução global, acontecendo, assim, o abandono do campo por ter a falsa sensação que é na cidade que ele encontrará suporte para seu sucesso e de sua família (MOURA, 2009).

No imaginário coletivo, considera-se apenas uma questão de tempo para que a população rural seja extinta e, por conseguinte, não se necessite mais de escolas no campo. A partir dessa visão, elaborou-se e difundiu-se, no imaginário coletivo nacional, que esse tipo de escola, sobretudo as escolas multisseriadas, assim como o local onde estão localizadas, são resquícios de um passado rural, sinônimo de atraso, e que estariam fadadas ao desaparecimento com o processo de urbanização (MATEDDI e MORETO, 2011).

Analisando os dados do Censo Escolar, existiam 107.432 escolas no território rural do Brasil em 2002. Em 2009, o número desses estabelecimentos de ensino reduziu-se para 83.036, significando o fechamento de 24.396 escolas no meio rural. Já em 2010, foi registrada a existência de 78.828 escolas, confirmando a manutenção do forte declínio ao longo dos últimos anos. Desse modo, aliado ao grave problema da abrupta redução do número de escolas, um dos grandes desafios enfrentados, no âmbito do direito à educação no campo, é garantir a oferta e criar condições de permanência dos alunos na escola (MOLINA e FREITAS, 2012).

Neste sentido, revela-se a necessidade de se trazer à tona questões que permeiam a realidade da educação no campo, inclusive questões sobre as classes multisseriadas, a formação dos professores, a efetividade dessas, e também como as práticas podem ser repensadas dentro da realidade local.

Atualmente a população de Santa Maria/RS é de 261.031 habitantes, dos quais somente $12.684(4,85 \%)$ residem na zona rural, resultado do intenso processo migratório do campo para as cidades (IBGE, 2010). A força de trabalho da população rural desta região está apoiada na agricultura familiar, bem como o ensino rural está concentrado em escolas de Ensino Fundamental, totalizando nove instituições e 1365 alunos matriculados. Dessas, sete possuem classes multisseriadas nos anos iniciais do Ensino Fundamental, representando 78\% da totalidade.

As características geográficas, sociais e culturais locais determinam que o ensino, nas

Geografia Ensino \& Pesquisa, v. 17, n. 2 p. 129-146, maio/ago. 2013

Escola do campo multisseriada: experiência docente séries iniciais, seja multisseriado na maioria das escolas rurais, segundo dados do Educacenso 2011. Diante disso, faz-se imprescindível definir as classes multisseriadas que, segundo Cardoso e Jacomeli (2010), são turmas nas quais um professor tem a responsabilidade exclusiva por dois ou mais níveis de escolaridade ao mesmo tempo e espaço. Cabe ressaltar que essa organização do ensino no Brasil está intrinsecamente ligada ao meio rural, uma vez que é, neste espaço, que essa realidade configura-se. 
No contexto de muitos países em desenvolvimento, incluindo o Brasil, o termo multisseriado, quase sempre, refere-se a turmas nas quais os alunos foram combinados por razões de necessidade, ao invés de escolha pedagógica. Os agrupamentos multisseriados combinados verticalmente são normalmente aplicados à realidade rural em situações que se tem um número reduzido de alunos por série, justificando a permanência deles nas escolas mais próximas de suas localidades, evitando, assim, que os estudantes percorram longos trechos até a área urbana ou que acabem evadindo (HARGREAVES, 2001; BERRY, 2001; COUTINHO e ABREU, 2011).

Neste contexto, o estudo aqui apresentado está focado na educação multisseriada dos anos iniciais do município de Santa Maria no RS, onde, através dos dados apresentados pelo senso local, bem como de uma prospecção exploratória e da experiência como docente em uma escola multisseriada do campo, pretende-se levantar as seguintes questões.

Primeiramente tratar-se-á da Educação do Campo e seus aspectos históricos e perspectivas; no seguinte, focar-se-á o Ensino Multisseriado observando sua problemática e desafios; e, por fim, apresentar-se-á a realidade local associada à experiência em uma Escola de campo Municipal de Ensino Fundamental multissérie, trazendo algumas reflexões da realidade vivida por um dos autores como docente desta Instituição. O levantamento foi enfocado para servir de objeto preliminar para análise do meio educacional como forma de percepção para novos rumos da problemática local, utilizando como amostragem real uma unidade escolar localizada no âmbito rural.

\section{Educação do campo: aspectos históricos e perspectivas}

Vive-se, no Brasil, um tempo de grande debate no que se refere à educação pública de qualidade (CHATTOPADHAY, 2012). Neste cenário, encontra-se a educação do campo.

Historicamente, a educação do campo nasceu como oposição a projetos de educação que buscavam uma visão instrumentalizadora, colocada a serviço das demandas de um determinado modelo de desenvolvimento do campo (que sempre dominou a chamada "educação rural"). Além disso, iniciou a favor da educação como formação integral do ser humano, uma vez que busca criar meios de fortalecer a identidade dos sujeitos do campo, afirmando uma educação emancipatória, vinculada a um projeto histórico, de longo prazo, de superação do modo de produção capitalista (TAFFAREL; SANTOS JUNIOR e ESCOBAR, 2010).

Assim, por muitos anos, no Brasil, o trabalho no campo foi visto como expressão de desigualdade social e reflexo da sobreposição de classe. Na década de 40, ainda se encontrava em vigência o ruralismo pedagógico, o qual se configurou numa tentativa de romper a questão social provocada pelo inchaço das cidades e incapacidade de absorção de toda mão-de-obra disponível pelo mercado de trabalho urbano. Nos estudos levantados, constata-se que, nas décadas de 40 e 50, foram criados programas voltados para atender a educação no espaço rural, lançados e implementados pelo Ministério da Agricultura, Ministério da Educação e Saúde Pública, baseados em modelos norte-americanos. Um dos programas que se destacou foi a "Campanha de Educação de Adultos" (CALAZANS, 1993).

$\mathrm{Na}$ tentativa de resolver os sérios entraves que permeiam a educação no campo, nos anos 1970 e 1980, foram desenvolvidos outros programas com o propósito de atender as peculiaridades das populações do espaço rural, tendo como foco principal diminuir com o analfabetismo (MOLINA e FREITAS, 2012). Em meio aos referidos programas, destacam-se o Edurural e o Mobral. O primeiro inicia-se no Nordeste entre os anos 1980 a 1985 projetado pela parceria entre Universidade Federal da Bahia (UFBA) e Governo Federal. Entre seus objetivos, estava presente o de melhorar as condições de ensino, recursos humanos e materiais. Para atingir estas metas foi efetivamente implementado uma adaptação curricular aos aspectos intelectuais, sociais e culturais para a vida e o trabalho no campo. Já o Mobral, caracterizou-

Geografia Ensino \& Pesquisa, v. 17, n.2 p. 129-146, maio/ago. 2013

Druzian, F.; Meurer, A. C

ISSN 2236-4994 I 131 
se como um projeto desenvolvido para combater o analfabetismo brasileiro (COUTINHO e ABREU, 2011).

Portanto, constata-se que a educação do campo até a década de 1990 foi menosprezada e tratada com desdém, quadro esse que vem mudando lentamente após essa década. As discussões e os debates acerca do assunto permeiam o ministério da educação através de movimentos interessados nessa problemática (VENDRAMINI, 2007).

Destaca-se, como uma respeitável e significativa mudança efetiva no que se refere à educação rural, o movimento nacional desencadeado para a construção de uma escola do campo, o qual estava atrelado ao processo de edificação de um projeto popular para o Brasil, que incluiu um novo projeto de desenvolvimento para o campo, como afirma Vendramini:

Nesta orientação, foram realizadas diversas conferências estaduais e nacionais, sendo a primeira conferência nacional, "Por uma Educação Básica do Campo", realizada em 1998 e organizada pelo MST, CNBB, UNICEF e UNESCO. Essa primeira Conferência inaugurou uma nova referência para o debate e a mobilização popular: Educação do Campo e não mais educação rural ou educação para o meio rural, ao reafirmar a legitimidade da luta por políticas públicas específicas e por um projeto educativo próprio para os sujeitos que vivem e trabalham no campo (VENDRAMINI, 2007, p.123).

Vedramini ainda ressalta que, na sequência:

O Ministério da Educação instituiu, em 2003, um Grupo Permanente de Trabalho Educação do Campo e, em 2004, criou a Secretaria de Educação Continuada, Alfabetização e Diversidade (SECAD), contemplando em sua estrutura a Coordenação Geral de Educação do Campo (VENDRAMINI, 2007, p. 124).

No que diz respeito à legislação, torna-se necessário destacar também que, a partir de diversas lutas (nacionais, estaduais e municipais), o Movimento da Educação do Campo acumulou um conjunto importante de instrumentos legais que reconhecem e validam as condições necessárias para que a universalidade do direito à educação seja exercida, respeitando as especificidades dos sujeitos do campo, tais como: Diretrizes Operacionais para Educação Básica das Escolas do Campo: Resolução CNE/CEB n 1/2002 e Resolução CNE/ CEB n ${ }^{\circ}$ 2/2008; Parecer n 1/2006 que reconhece os Dias Letivos da Alternância, também homologado pela CEB; Decreto ${ }^{\circ}$ 7.352, de 4 de novembro de 2010, que dispõe sobre a Política Nacional de Educação do Campo e sobre o Programa Nacional de Educação na Reforma Agrária/PRONERA (MOLINA e FREITAS, 2012).

Mesmo com essa evolução advinda da preocupação com as escolas do campo, ainda é grande, se não dizer necessário e emergente, desenvolver efetivamente um modelo de educação do e no campo embasado na realidade dos sujeitos que estão envolvidos nesta problemática. Entre as principais problemáticas paralelas a serem ressaltadas, destaca-se a situação socioeconômica das famílias residentes no campo. Garantir condições para a reprodução material da vida destas famílias, para que possam manter as crianças nos processos educativos por longos períodos, implica garantir o acesso à terra e aos recursos naturais, a partir dos quais os sujeitos do campo sobrevivem, buscando sua autossustentabilidade.

Geografia Ensino \& Pesquisa, v. 17, n.2 p. 129-146, maio/ago. 2013

Escola do campo multisseriada: experiência docente

Incluindo-se a isso, precisa-se pensar nas transformações de todo o conjunto que envolve o processo de ensino presente em cada contexto econômico, político, social e cultural neste momento histórico, ou seja, a inserção geográfica e a identificação política, na própria realidade cultural do campo, tornam-se premissas fundamentais de sua implementação, ao invés de seguir uma concepção pedagógica pronta e acabada. 


\section{Ensino multisseriado: problemática e desafios}

Ao tratar de classes multisséries, primeiramente, faz-se preciso relacioná-las ao espaço rural, uma vez que esse é o território que tais turmas existem concretamente. Embora se apresentem em outros cenários, é no campo que elas se constituem na sua máxima expressão identitária.

Apesar de tal entendimento, compreender as classes multisseriadas do campo, para discutir a qualidade do ensino que oferecem e as razões da sua permanência, coloca desafios aos que desejam estudá-las. Isso ocorre por que, quando o multisseriamento é abordado, o que se busca é sua superação, pois esse modelo de organização da educação do campo apresentouse durante muito tempo, senão até hoje, como distante do paradigma curricular moderno, urbano e seriado, visto como de má qualidade, atrasado, distante dos padrões de qualidade por diversos motivos. Entre os mais destacados, elencam-se a baixa qualificação dos professores, a falta de condições e materiais didáticos, a complexidade do exercício da docência em classes multisseriadas, o atraso da formação escolar do sujeito do campo, entre outros fatores que levam a está visão (HARGREAVES, 2001; BERRY, 2001; ROCHA e HAGE, 2010).

Dessa forma, a multissérie constitui principalmente uma realidade eminentemente do campo. Nas turmas multisseriadas, existe um único professor, assumindo, muitas vezes, múltiplas funções, de faxineiro a professor, para duas, três e até quatro séries diferentes ao mesmo tempo e no mesmo espaço. A existência das escolas unidocentes denuncia a desvalorização e a sobrecarga de trabalho do professor, que atende a demanda de várias séries e ainda desempenha todas as funções no âmbito da escola, desde a docência, passando pelo preparo da merenda, até a limpeza do estabelecimento (FAGUNDES e MARTINI, 2003).

Entretanto, a constituição dessas classes é formada como uma solução adotada em diferentes países, principalmente para permitir que a população do espaço rural tenha acesso à educação, já que a baixa densidade demográfica nas respectivas áreas e o consequente baixo número de alunos inviabilizam a organização seriada, justificando a falta de criação de turmas voltadas ao atendimento de séries ou faixa etária específica, tornando-se uma imposição, muitas vezes, vertical das políticas públicas (LITTLE, 2001; BERRY, 2001; HARGREAVES, 2001; COUTINHO e ABREU, 2011).

Apesar de ser necessidade, no meio rural, a multissérie ainda é uma extensão do paradigma da escola seriada "urbanocêntrica", pois não possui um tratamento diferenciado. Trata-se de uma realidade ignorada, inclusive nas estatísticas sobre educação no país.

$\mathrm{Na}$ literatura, evidencia-se que a história da classe multisseriada das escolas do campo foi sustentada por políticas compensatórias no que diz respeito a solucionar o acesso à escolarização de um número reduzido de crianças e jovens existentes no campo, como expõe Hage:

Esse discurso se assenta no paradigma urbanocêntrico, de forte inspiração eurocêntrica, que estabelece os padrões de racionalidade e de sociabilidade ocidentais como universais para o mundo, impondo um único modo de pensar, agir, sentir, sonhar e ser como válido para todos, independentemente da diversidade de classe, raça, etnia, gênero e idade existente na sociedade. Esse paradigma exerce muita influência sobre os sujeitos do campo e da cidade, levando-os a estabelecer muitas comparações entre os modos de vida urbanos e rurais, entre as escolas da cidade e as do campo, e a compreender que as do campo devem seguir os mesmos parâmetros e referências daquelas da cidade, se quiserem superar o fracasso escolar e se tornar escolas de qualidade (HAGE, 2011, p. 105).

Geografia Ensino \& Pesquisa, v. 17, n.2 p. 129-146, maio/ago. 2013

Druzian, F.; Meurer, A. C

ISSN 2236-4994 I 133 
A organização de forma seriada exige o trabalho pedagógico de forma fragmentada, fazendo com que as atividades de planejamento, de currículo e de avaliação sejam desenvolvidas isoladamente para cada uma das séries, acumulando vários alunos reprovados por não conseguirem supostamente seguir o processo linear. Logo, é evidenciada a necessidade de organizar e homogeneizar os processos. Rocha e Hage (2010) relatam que a organização seriada está em crise por ser antidemocrática, classificatória e segregadora, pois quando se busca entender como a mente humana aprende, torna-se sem sentido propor que as escolas do campo, multisseriadas ou não seriadas, virem seriadas.

Desta forma, percebe-se que tanto o modelo seriado quanto a multissérie possuem desafios em busca de um processo de ensino-aprendizagem de qualidade. Segundo Little (2001), Hargreaves (2001) e Berry (2001), a maioria das pesquisas sobre ensino multisseriado, também a nível internacional, concentra-se no impacto sobre a aprendizagem dos alunos. Um conjunto mais limitado de estudos exploraram a prevalência, localização e invisibilidade de ensino multisseriado, apesar das variações relacionadas ao contexto político e ao nível de desenvolvimento de cada região ou país.

Os desafios apontam o enredamento que configura a realidade enfrentada por professores e alunos das instituições do campo multisseriadas. Esse quadro tem demandado, nesses últimos anos, apontar possibilidades de intervenção e propostas de solução para essa problemática: que sejam contextualizadas e viáveis e que atendam às necessidades e às expectativas do poder público, dos movimentos e organizações sociais, dos órgãos de fomento e dos pais, educadores e estudantes envolvidos com as escolas ou turmas multisseriadas (HAGE, 2011).

Para tanto, precisa-se superar as visões tão negativas do campo e de seu ensino multisseriado, construindo uma nova proposta educativa para a escola do campo organizada em multisseriação, a qual leve em consideração os seguintes aspectos: a necessidade de investigar as diferentes formas de organização do trabalho pedagógico realizada em turmas diferenciadas por idade e aprendizagens; a reformulação da proposta político-pedagógica das instituições e do currículo rurais; e as políticas públicas que busquem a qualidade e as retirem do anonimato (HARGREAVES, 2001; BERRY, 2001; ROCHA e HAGE, 2010). Nesse sentido, Molina e Freitas reforçam que:

Este é um dos desafios e, ao mesmo tempo, uma das possibilidades da escola do campo: articular os conhecimentos que os educandos têm o direito de acessar a partir do trabalho com a realidade, da religação entre educação com a cultura e com os conhecimentos científicos a serem apreendidos em cada ciclo da vida e de diferentes áreas do conhecimento. Surge daí uma grande potencialidade de dimensões formativas que foram separadas pela cultura fragmentada e individualista do capital, embora na vida real se apresentem articuladas, imbricadas, às vezes mesmo em simbiose. Além de contribuir com a construção da autonomia dos educandos, essas articulações propiciam a internalização da criticidade necessária à compreensão da inexistência da neutralidade científica, com a localização da historicidade dos diferentes conteúdos e dos contextos sócio-históricos nos quais foram produzidos (MOLINA e FREITAS, 2012, p. 27).

Atribui-se à escola do campo uma importante contribuição no processo mais amplo de transformação social, o qual se faz através da intencionalidade de um projeto de formação de sujeitos que percebam criticamente as escolhas e premissas socialmente aceitas, bem como

Geografia Ensino \& Pesquisa, v. 17, n. 2 p. 129-146, maio/ago. 2013

Escola do campo multisseriada: experiência docente que sejam capazes de formular alternativas de um projeto político. À escola do campo, colocase o desafio de formular e executar um projeto de educação integrado a um projeto político de transformação social liderado pela classe trabalhadora, o que exige a formação integral dos trabalhadores do campo, no sentido de promover simultaneamente a transformação do mundo e a autotransformação humana (MOLINA e FREITAS, 2012).

Por isso, a escola do campo, como parte de um projeto maior da classe trabalhadora, 
propõe-se a construir uma prática educativa que efetivamente venha ao encontro dos anseios dos sujeitos que residem no espaço rural, propiciando melhores condições e permanência a eles.

\section{Escola do campo: condições e possibilidades}

A temática das classes multisseriadas, além de ser um objeto de investigação quase inexplorado, sobrevive a mais de cem anos. Inclusive, adentrou no século XXI sem ser extinta pelas novas formas de organização escolar propostas pelas políticas públicas educacionais, apesar de, no Rio Grande do Sul, ter sido reduzido, em aproximadamente, 3 vezes entre 1998 e 2007, concentrando-se principalmente nas zonas rurais (Figura 1). Esses valores são aproximadamente 3 vezes maiores dos existentes nos Estados do Paraná e em Santa Catarina; no entanto, 3 vezes menores dos existentes na Bahia, com 93.884 turmas em âmbito nacional (Cardoso et al., 2010). Em função disso, para Little (2001), como ocorre com a metodologia monosseriada, o conhecimento das estratégias do ensino multisseriado é fundamental na formação básica de todos os professores, além da formação continuada.

Figura 1 - Comportamento dos números de Turmas Multisseriadas no Ensino Fundamental entre 1998-2007 no Rio Grande do Sul (CARDOSO e JACOMELI, 2010).

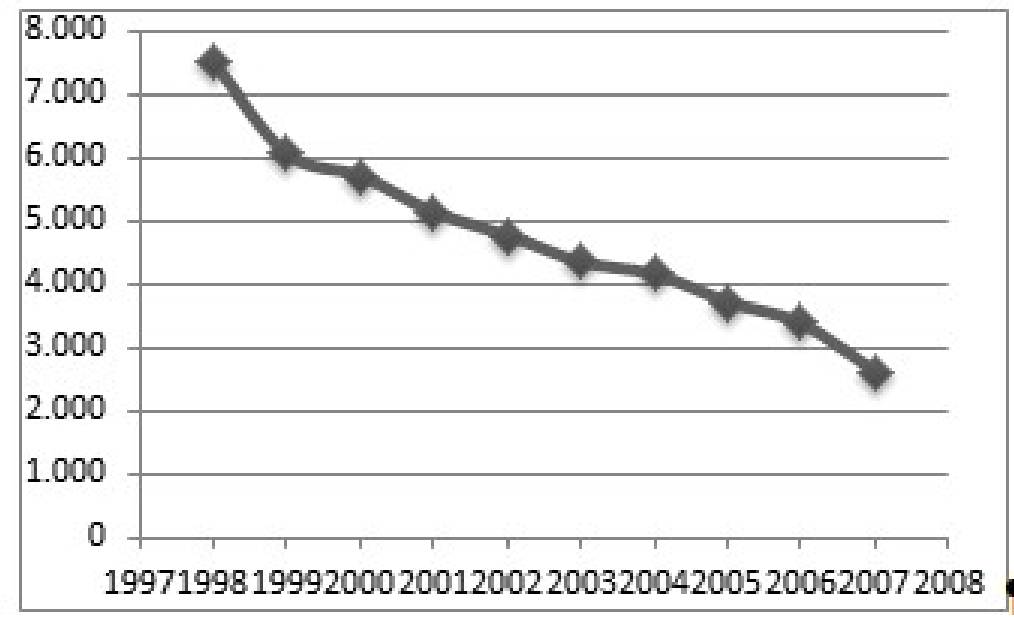

O município de Santa Maria situa-se no centro do estado do Rio Grande do Sul, sendo considerado o $5^{\circ}$ mais populoso do estado, possuindo 261.031 habitantes, sendo 12.638 localizados no meio rural, dividido em 10 distritos, com exceção do $1^{\circ}$ Distrito (Sede), (IBGE, 2010). Cabe destacar que Santa Maria é considerada como cidade universitária, graças à Universidade Federal de Santa Maria (UFSM), criada por José Mariano da Rocha Filho, em 1960.

Nesse contexto, até o ano de 1989, Santa Maria possuía uma das maiores redes de escolas do Estado, contando com um total de 170 escolas, das quais 126 (74\%) localizavamse na zona rural do Município. As escolas, na sua maioria, eram de classes multisseriadas, atendidas por um só professor, que trabalhava com quatro níveis de ensino em uma só sala ( $1^{\text {a }}$ à $4^{\text {a }}$ série), enfrentando diversas dificuldades, tais como: grande repetência dos alunos; evasão escolar, principalmente, em época de colheita; falta de espaço físico; dificuldades de acesso às escolas tanto do aluno quanto do professor; e unidocência em classes multisseriadas (SPIRONELLO e BEZZI, 2001).

Com base na realidade exposta, a Prefeitura do Município de Santa Maria passou a elaborar um diagnóstico, com a finalidade de melhorar a qualidade de ensino no espaço

Geografia Ensino \& Pesquisa, v. 17, n.2 p. $129-146$, maio/ago. 2013

Druzian, F.; Meurer, A. C

ISSN 2236-4994 I $\quad 135$ 
do campo, ocorrendo, em algumas escolas, uma melhoria na infraestrutura e na ampliação dos prédios. Além disso, o sistema de transporte escolar foi reorganizado para atender essa população. Efetuou-se, também, a compra de equipamentos para o desenvolvimento tanto das atividades administrativas quanto das pedagógicas. Todas essas ações configuraram um projeto piloto que ficou conhecido como "Nuclearização de Escolas da Zona Rural" de Santa Maria (MOURA, 2009).

Assim, esse projeto constituiu-se em um processo gradativo de agrupamento de pequenas escolas com classes multisseriadas e unidocentes em uma Escola-Núcleo, apresentando, desse modo, características específicas de trabalho e organização com um plano pedagógico vinculado às necessidades da população que reside no espaço rural do Município. Diante desse quadro, as Escolas-Núcleo vieram com o intuito de modificar o ensino no meio rural, possibilitando aos jovens um ensino de melhor qualidade, oportunizando a conclusão do Ensino Fundamental e abrindo espaço para construção de um futuro mais sólido e aberto a novas perspectivas, como relata os autores abaixo:

No discurso de gestores públicos das várias esferas governamentais, esse aumento significativo do investimento no transporte escolar no período mais recente associado ao processo de nucleação das escolas, de forma recorrente, tem sido apresentado enquanto elemento estratégico de sua política educacional implementada e enquanto expressão do compromisso assumido para assegurar a todos os estudantes do meio rural o direito de acessar a Educação Básica (BARROS e HAGE, p. 12, 2011).

Segundo os dados do Educacenso de 2011, a rede municipal de Santa Maria atende aproximadamente 19.338 alunos, distribuídos em oitenta escolas de Educação Infantil, Ensino Fundamental, Educação de Jovens e Adultos (EJA) e Ensino Profissionalizante (EMAI), contando com um quadro de 1558 professores. Nesse contexto, 71 escolas situam-se no $1^{\circ}$ Distrito/sede que é considerado urbano, sendo 45 de Ensino Fundamental, e 9 escolas situamse no campo, distribuídas nos demais distritos do município, conforme Tabela 1.

Tabela 1- Número de escolas de Ensino Fundamental, alunos e classes multisseriadas nas escolas do campo por Distrito de Santa Maria, em julho de 2012.

Geografia Ensino \& Pesquisa, v. 17, n. 2 p. $129-146$, maio/ago. 2013

Escola do campo multisseriada: experiência docente

\begin{tabular}{|c|c|c|c|}
\hline Distrito & EMEF1 & Alunos & Classes Multisseriadas \\
\hline $2^{\circ} /$ São Valentim & José Paim de Oliveira & 147 & 2 \\
\hline $3^{\circ} /$ Pains & $\begin{array}{c}\text { Bernardino Fernandes } \\
\text { João da Maia Braga } \\
\text { Pedro Kunz }\end{array}$ & 119 & \\
\hline $4^{\circ} /$ Arroio Grande & - & 387 & -- \\
\hline $5^{\circ} /$ Arroio do Só & - & 63 & 2 \\
\hline $6^{\circ} /$ Passo do Verde & Irineo Antoline & 33 & 2 \\
\hline $7^{\circ} /$ Boca do Monte & João Hundertmarck & 244 & -- \\
\hline $8^{\circ} /$ Palma & Major Tancredo Penna de & 118 & - \\
\hline $9^{\circ} /$ Santa Flora & Moraes & 157 & 2 \\
\hline $10^{\circ} /$ Santo Antão & Intendente Manoel Ribas & 97 & 11 \\
\hline Total & 9 & 1365 & 2 \\
\hline
\end{tabular}

${ }^{1}$ EMEF (Escola Municipal de Ensino Fundamental).

(-) Distrito sem escola Municipal.

(-) Escola sem Classes Multisseriadas.

Fonte: Dados não publicados, pesquisados pela Secretaria Municipal de Educação de Santa Maria/SMED-julho de 2012

Dentre as escolas descritas na Tabela 1, constata-se que o reduzido número de alunos 
exige a necessidade de classes multisseriadas, tornando-se uma realidade nas escolas do campo da região de Santa Maria. Salienta-se que a multissérie ocorre nas classes de Educação Infantil (chamadas de multietárias, nessa modalidade de ensino) e nas séries iniciais do Ensino Fundamental, enquanto que, nos Anos Finais, o ensino organiza-se a partir do modelo seriado. As escolas multisseriadas do campo de Santa Maria representam, aproximadamente, 20\% do total de escolas de Ensino Fundamental do município.

Esse subitem da prospecção também foi relatado em função de reflexos da experiência docente com turmas multisseriadas do campo no Município de Santa Maria. Nesse contexto, relata-se a experiência docente vivida na EMEF Major Tancredo Penna de Moraes, situada no Distrito de Palma. A sua localização específica é na Rodovia RST 287, Km 23, Palma - $8^{\circ}$ Distrito de Santa Maria/RS, CEP: 97119-000, a uma distância de $25 \mathrm{Km}$ do centro da cidade de Santa Maria, ocupando uma área total de $5.000 \mathrm{~m}^{2}$.

O distrito de Palma está divido em seis comunidades: Faxinal da Palma, Linha Sete, Vista Alegre, Vale dos Panos, Santa Teresinha e Quilombo (destaca-se a existência do Quilombo Ernesto Pena, formado por escravos remanescentes da Fazenda da família Pena).

A comunidade educacional da EMEF Major Tancredo Penna de Moraes abrange ainda alunos de Arroio Grande, Vila Figueira, Arroio do Só, bem como de Restinga Seca e Silveira Martins, municípios localizados na limitação geográfica do município de Santa Maria. Cabe ressaltar que a economia do distrito está alicerçada na agricultura familiar, com algumas propriedades com criação de animais, horta e algumas atividades agrícolas, como plantio de arroz, batata, milho, feijão, amendoim entre outros, prioritariamente para a subsistência familiar.

A EMEF Major Tancredo Penna de Moraes resultou do processo de nucleação do ensino (1991 a 1994), no qual as escolas isoladas das comunidades vizinhas (Tabela 2) foram integradas. Portanto, a escola formou-se a partir do fechamento de oito pequenas outras escolas multisseriadas localizadas nas comunidades próximas. Com o processo de nucleação, o transporte escolar passou a percorrer pelas localidades, em aproximadamente, uma distância de $30 \mathrm{Km}$, trazendo os alunos para a escola núcleo. A princípio, mais especificamente entre 1994 a 2009, as aulas aconteciam em horário alternado, ou seja, anos iniciais à tarde, e anos finais pela manhã. A partir de 2010, em horários integral-alternado, ou seja, nas segundas, terças e quintas-feiras, os alunos que cursam as séries iniciais têm aula (Pré, $1^{\circ}, 2^{\circ}, 3^{\circ}, 4^{\circ}$ e $5^{\circ}$ anos); já nas segundas, quartas e sextas-feiras, os estudantes que cursam as séries finais $\left(6^{\circ}\right.$, $7^{\circ}, 8^{\circ}$ E $\left.9^{\circ}\right)$. Com o agrupamento das pequenas escolas, a EMEF Major Tancredo Penna de Moraes passou a ter um número significativo de alunos, em torno de 250, em 1995. Fator esse que a transformou em escola seriada.

Tabela 2-Escolas nucleadas que formaram a atual EMEF Major Tancredo Penna de Moraes em 1995 com as respectivas localidades.

\begin{tabular}{|c|c|}
\hline Localidade & Escolas Multisseriadas \\
\hline Faxinal da Palma & Escola Municipal Faxinal da Palma \\
\hline Faxinal da Palma & Escola Municipal Benjamin Constant \\
\hline Faxinal da Palma & Escola Municipal Pillon \\
\hline Santa Terezinha & Escola Municipal Olavo Bilac \\
\hline Linha Sete & Escola Municipal Santa Augusta \\
\hline Vale dos Panos & Escola Municipal Vale dos Panos \\
\hline Vila Fighera & Escola Municipal Santo Antônio \\
\hline São Sebastião & Escola Municipal São Sebastião \\
\hline Total & 8 \\
\hline
\end{tabular}

Geografia Ensino \& Pesquisa, v. 17, n.2 p. $129-146$, maio/ago. 2013

Druzian, F.; Meurer, A. C

ISSN 2236-4994

Fonte: Dados não publicados, pesquisados pela Secretaria Municipal de Educação de Santa Maria/SMED-julho de 2012 
Nesta perspectiva, estudos realizados pelo censo demográfico 2010 do IBGE demonstraram que o número de pessoas que moram em áreas rurais continua diminuindo no país. De acordo com a pesquisa, a população rural, no país, perdeu 2 milhões de pessoas entre 2000 e 2010, o que representa metade dos 4 milhões que foram para as cidades na década anterior (IBGE, 2010).

Não diferente, na região de Santa Maria, com o passar dos anos, a população rural tem diminuído e as turmas de anos iniciais das escolas do campo passam a ter um reduzido número de alunos, tornando-se novamente multisseriadas, a partir de agosto de 2011.

A EMEF Major Tancredo possui atualmente cento e dezoito alunos (Tabela 1), divididos em 8 turmas de pré-escola ao $9^{\circ}$ ano, distribuídos da seguinte forma: pré-escola $\mathrm{A}$ e $\mathrm{B}, 1^{\circ}$ e $2^{\circ}$ anos, 3 e $4^{\circ}$ anos, $5^{\circ}$ ano, $6^{\circ}$ ano, $7^{\circ}$ ano, $8^{\circ}$ ano e $9^{\circ}$ ano. Desse modo, opera hoje 3 classes multisseriadas, distribuídas em pré-escola, nível A e B - turma 1 (18 alunos), $1^{\circ}$ e $2^{\circ}$ - turma 2 (16 alunos), e $3^{\circ}$ e $4^{\circ}$ - turma 3 (17 alunos).

A partir de dados coletados através de questionários enviados às famílias, no último trimestre de 2010, construiu-se o perfil da comunidade escolar. A maior parte das famílias mora nas localidades que circundam a escola há mais de 15 anos. Também, é importante ressaltar que existem famílias itinerantes, que ficam apenas durante o tempo da colheita do arroz e da batata inglesa, que são produtos típicos da comunidade. Outro aspecto a ser considerado é a significativa migração da cidade para o campo, constituindo os bolsões de casebres e famílias acomodadas em terrenos na beira das estradas (Dados do Projeto Político-Pedagógico da Escola/PPP, 2011).

Como resposta à pesquisa, na educação, as famílias acreditam na formação vivenciada na Escola e gostam do ambiente escolar. Também, todas as famílias pesquisadas desejam que a escola prepare os seus filhos para continuarem os estudos, não desejando que eles permaneçam no campo. Fato esse que contraria o interesse de alguns alunos que pensam em ficar nas suas localidades ou estudar e voltar para o campo.

Dessa forma, através do levantamento feito pelas pesquisas, notou-se que a maioria dos alunos desta instituição tem escassos recursos pessoais e suas famílias não possuem condições necessárias para fornecer grande apoio. De maneira geral, existe a falta de recursos das famílias, ou recursos extremamente limitados, uma vez que, aos sujeitos do campo, vêm sendo delegadas políticas públicas ineficazes ou impróprias a sua realidade, como afirma:

O campo, no contexto brasileiro, apresenta um quadro resultante de políticas
publicas insuficientes ou inadequadas a sua realidade. Historicamente, o que
e dado como direito da população em geral tem sido negado a população
do campo, que vem amargando os piores índices socioeconômicos, como
renda, analfabetismo e acesso as tecnologias, alem de essa população ser
relegada a uma educação precária, com currículos que não condizem com
suas necessidades, com uma infraestrutura deficitária e com professores sem
formação adequada. Faz-se necessário, então, compreender melhor esse
contexto, que requer acesso às tecnologias e uma maior articulação entre
a formação dos professores, as diferentes linguagens, a cultura digital e as
praticas pedagógicas, de forma a proporcionar a compreensão da realidade
do campo e as possibilidades que a tecnologia oferece para sua transformação
(BONILLA e HALMANN, 2011, p. 286).

Geografia Ensino \& Pesquisa, v. 17, n. 2 p. 129-146, maio/ago. 2013

Escola do campo multisseriada: experiência docente
Nesse sentido, relata-se que os professores da EMEF Major Tancredo Penna de Moraes enfrentam dificuldades com os materiais de apoio didático-pedagógicos, bem como com as novas mídias e tecnologias aplicadas à educação, uma vez que estes subsídios não estão vinculados à realidade do campo, sendo planejados e distribuídos a nível nacional e, na maioria das vezes, de acordo com a realidade urbana.

Conforme Rocha e Hage (2010), a maioria dos materiais de apoio didático-pedagógicos 
elaborados e distribuídos para os anos iniciais do Ensino Fundamental apresentam algumas limitações. Os professores costumam relatar que estes materiais são difíceis de entender e não apresentam sintonia com o contexto rural. $O$ fato é que se torna especialmente difícil de utilizar estes materiais nas salas de aula multisseriadas, nas quais os professores enfrentam um maior grau de dificuldade em função dos diferentes níveis de escolaridade, bem como da sobrecarga de trabalho exigido do profissional que atende sozinho os diferentes níveis. Embora se perceba alguns esforços do poder público para oferecer melhores condições de infraestrutura e didático-pedagógicas, o quadro-negro continua sendo o recurso pedagógico mais usado.

Apesar do reconhecimento da necessidade e da importância das escolas multisseriadas, nem sempre há uma completa consciência das dimensões reais da educação multisseriada e seu potencial para todas as situações com grande diversidade. Rocha e Hage, (2010) também relatam que os professores não são adequadamente preparados para trabalhar nesta realidade, apresentando dificuldade em organizar o processo pedagógico nas classes multisseriadas. Fator esse que ocorre, muitas vezes, por trabalharem com a ideia de união de várias séries e, consequentemente, com a elaboração de tantos planos de ensino e de avaliação da aprendizagem diversificados para cada ano. Percebe-se que esses estão angustiados e ansiosos na tarefa de trabalhar simultaneamente, alunos em vários níveis de aprendizagem, de diferentes idades. Para Hage (2010), as estratégias de avaliação para séries multisseriadas precisam ser empregadas; portanto, os professores precisam de orientação, formação e exemplificação relativa para efeito de formação.

A pesquisa de Gatti e Davis (1993) contribui para uma reflexão sobre o multisseriamento por apontar para a necessidade de soluções ao seu enfrentamento, e apresenta algumas alternativas aos problemas levantados:

\begin{abstract}
Dobrar a jornada diária de trabalho do professor, de forma que em cada período se conte, em sala de aula, com apenas duas séries [...] essa proposta está condicionada à garantia de que também a remuneração do docente será dobrada. Quaisquer que forem as soluções levantadas para o problema da multisseriação, o central é aprofundar maneiras mais eficientes (e não estigmatizantes) de se agregar os alunos, de se transformar os currículos das escolas rurais em conhecimentos concretos e de se estabelecer critérios confiáveis de avaliação. Muito da experiência acumulada pelo professorado leigo pode ser aproveitada, construindo-se, em conjunto, não só os conteúdos como também as formas mais efetivas de se transmitir o conhecimento por meio da prática pedagógica (GATTI e DAVIS, 1993, p. 161).
\end{abstract}

Apesar das alternativas indicadas, as autoras são contundentes quando afirmam que, geralmente, a regra nas formações oferecidas ao professorado do campo é homogeneizar o heterogêneo, partindo do pressuposto de que é preciso fazer uso de mecanismos mais ou menos coercitivos para que se cumpram "disposições oficiais, cujos objetivos [...] nem sempre são entendidos" (GATTI e DAVIS, 1993, p. 157). Colocam, ainda, que a escola do campo representa, para os alunos que atendem a uma oportunidade ímpar de aprendizagem sistemática de bens universais, como a leitura, a escrita, a contagem básica e os conceitos científicos iniciais sobre a realidade. No entanto, observa-se que

seu modo de operar impede o efetivo cumprimento daquilo que dela se poderia esperar, fornecendo sim, a duras penas, tão somente fragmentos de conhecimentos que não podem ser úteis nem para a vida no campo, nem para um possível projeto de vida urbano (GATTI e DAVIS, 1993, p.148).

Os autores também levantam a necessidade de buscar soluções para o difícil problema da multisseriação, uma vez que essa situação é enfrentada pela grande maioria dos docentes em sala de aula.
Geografia Ensino \& Pesquisa, v. 17, n.2 p. 129-146, maio/ago. 2013

Druzian, F.; Meurer, A. C

ISSN 2236-4994 I 139 
Diante dos inúmeros problemas ora decorrentes da fragmentação do conteúdo, ora baseadas na interdisciplinaridade ao longo da atuação enquanto docente, também não se pode deixar de concordar que a escola multisseriada pode ser compreendida como uma organização que possibilita o desenvolvimento de um processo educativo diferente, em que os alunos de faixas etárias e experiências diversas podem participar e criar formas coletivas de organização do conhecimento até com maior maturidade, quando comparada a metodologia seriada.

Parece evidente, como afirmam Berry (2001); Hargreaves (2001); Arroyo, Caldart e Molina, (2011) que a escola multisseriada pode ser uma oportunidade dos professores oferecer um apoio significativo à comunidade e obter um bom apoio dos pais, tomando-se iniciativas positivas e de ação efetiva para melhorar os resultados dos alunos. A descrença quase que generalizada em relação às classes multisseriadas decorre, muitas vezes, do desconhecimento da qualidade e da possibilidade de inovação que essa metodologia pode apresentar, assim como se ignora a importância dessas escolas na cultura e na vida social das comunidades rurais.

Está-se, enquanto escola EMEF Major'Tancredo Penna de Moraes, associada às diretrizes municipais reformulando os planos de estudo para adaptá-los a uma nova organização do ensino, de modo que se possa oferecer qualidade no processo de ensino-aprendizagem. Há referências no novo foco pedagógico do Programa da Escola Ativa (PEA), em que o processo de aprendizagem ocorra de forma ativa considerando os diferentes ritmos e níveis, centrada no aluno, e em sua realidade social, sendo o professor um facilitador e estimulador deste trabalho, bem como, da avaliação contínua e a promoção flexível. Para isso, segundo Rocha e Hage, (2010), faz-se o uso de dinâmicas de trabalho em grupo, ensino por meio de módulos e material didático produzidos exclusivamente para o Programa, estimulando a participação da comunidade e a formação continuada dos professores.

Contudo, a expectativa produzida pelo Programa Escola Ativa deixou a desejar, uma vez que o objetivo dele pauta-se na busca de melhores índices na qualidade do desempenho escolar em classes multisseriadas, mas não tem sido alcançado. Percebe-se que o referido programa deixa lacunas na implementação de sua proposta, a começar pela estrutura precária das escolas multisseriadas e da falta de formação de seus profissionais, bem como, a limitação das secretarias estaduais e municipais frente às necessidades para implementar o programa e, até mesmo, o atraso na distribuição do material didático-pedagógico que pertence a ele (D' AGOSTINI; TAFFAREL e SANTOS JÚNIOR, 2012).

Essa incongruência entre a realidade das salas de aula e a intenção pedagógica do sistema está recebendo atenção. Uma das mais importantes para elevar os padrões do ensino multisseriados tem surgido em parceria com a UFSM e a Prefeitura Municipal de Educação, através de projetos para escola, universidade e mantenedora confrontar os saberes, buscando soluções para a melhoria na qualidade de ensino rural.

Um desses projetos intitula-se PROGRAMA SOCIAL DE CIDADANIA UFSM/ CEFD (Centro de Educação Física e Desportos) e PREFEITURA MUNICIPAL de SANTA MARIA/SME (Secretaria Municipal de Educação), que consiste na implantação de um laboratório de prática pedagógica e estimulo a docência para alunos em formação inicial da UFSM, bem como a constituição de um grupo de estudo e formação continuada (professor supervisor da escola municipal/SME/CEFD/UFSM), em atendimento a um dos objetivos da UFSM relativo à questão da responsabilidade social com a comunidade local e regional. Para tanto, essa iniciativa conta com a parceria da UFSM, através dos diferentes Centros Universitários (CEFD; CAL-Centro de artes e letras; CT-Centro de Tecnologia; CE-Centro de Educação) e da SME. As atividades pedagógicas do referido projeto ocorrem nas dependências do CEFD/UFSM, integradas ao projeto pedagógico da escola, complementando as atividades curriculares, sob a coordenação de docentes vinculados aos diferentes Centros Universitários da UFSM (Pedagogia/CE; Música e Literatura/CAL; Educação Física/CEFD e Informática/ CT) e bolsistas/educadores atuantes nos cursos de graduações envolvidos, os quais são os 
encarregados do planejamento e da atuação direta com as crianças/adolescentes regularmente matriculados na EMEF Major Tancredo Penna de Moraes.

O programa acontece uma vez por semana, aos sábados pela manhã, com distintos grupos organizados por faixa etária (grupos de 20 alunos), nos meses de abril a novembro desde 2011, escolhidos pela equipe diretiva/pedagógica da escola e da SME/SM, dando prioridade aos alunos com problemas de relacionamento social, aprendizagem cognitiva e aos que se encontram em risco e vulnerabilidade social, perfazendo um total de quatro (4) horas de envolvimento semanal. As oficinas pedagógicas são organizadas em forma de rodízio, como complemento das aulas curriculares, tratando temáticas específicas construídas pelo grupo de estudo. As oficinas pedagógicas no programa têm autonomia para discutir e operacionalizar temas específicos: jogos populares; formação esportiva; tênis/jogos de raquete; capoeira; dança; desenho; pintura; leitura e hora do conto; inclusão digital; jogos pedagógicos; música; literatura; reforço escolar; entre outros.

Além desse programa recente, a EMEF Major Tancredo foi contemplada com o projeto Educação do Campo (PIBID/UFSM), o qual objetiva a criação de um campo de atuação de educadores em formação envolvendo a prática educacional nas escolas das redes públicas e o desenvolvimento de estratégias educacionais inovadoras e interdisciplinares nas diferentes áreas envolvidas, trabalhando com o Ensino Fundamental, a partir da inserção e interação das várias licenciaturas da UFSM, fundamentando-se em uma proposta de Educação para o campo, designando-o como espaço geográfico de vida, contemplando todas as dimensões da existência humana.

Um diagnóstico da situação das escolas rurais e de seu ambiente social e cultural foi realizado pela Secretaria Municipal de Educação/SMED e repassado aos gestores das escolas do campo no ano de 2011. Os resultados obtidos permitiram identificar os problemas, as causas e as possíveis soluções, bem como os fatores e as intervenções necessárias para atingir uma educação de qualidade nas escolas do campo. Diante disso, a escola EMEF Major Tancredo Penna de Moraes busca levar o sujeito do campo a reconhecer-se como agente ativo na transformação de sua realidade, levando-o a viver e ser autossustentável no meio rural. Objetivo esse que estamos com dificuldade de alcançar, pois a maioria das famílias que tem filhos estudando na escola não vê, no campo, um futuro profissional promissor para seus filhos, segundo dados levantados através de pesquisas da escola (PPP, 2011).

Acredita-se que a escola seja o primeiro passo para que os sujeitos conheçam novos mundos, novas ideias, ou melhor, é o lugar que serve de ponte para o desenvolvimento e a aprendizagem. Para isso, procurou-se partir sempre da realidade vivida pelos alunos, embasando a prática no coletivo, ou seja, na ação conjunta com docentes, alunos e parceiros.

Portanto, considera-se que seja mais do que preciso elaborar uma proposta educativa para as escolas do e no campo, buscando um novo projeto de aprendizagem alicerçado às necessidades populares dos diferentes sujeitos que no espaço rural residem e constroem suas relações. Além disso, para que se busque a edificação de políticas públicas que incentivem as instituições de pesquisa e de extensão a implementar projetos conjuntos na sociedade, visando, de forma efetiva, a transferência de tecnologia e a inovação dos processos. Tudo isso para construir um caminho de mão dupla, no qual a sociedade e as instituições aproximam-se, a fim de resolver os problemas conjuntamente.

Geografia Ensino \& Pesquisa, v. 17, n.2 p. $129-146$, maio/ago. 2013

\section{Conclusão}

Reconhece-se a limitação de estudos por falta de dados estatísticos atuais e localizados; Druzian, F.; Meurer, A. C

ISSN 2236-4994 I 141 porém, pretendeu-se abrir campo e interesse para futuros estudos que visem a levantar a realidade da educação do campo no município de Santa Maria/RS. Concorda-se também 
que é difícil se contrapor às visões tão negativas do campo e de suas escolas, uma vez que reproduzem visões contraproducentes dos seus povos e das instituições do campo. No entanto, acredita-se que, com estudos e intervenções mais específicos, essa imagem pode ser modificada, considerando ser uma oportunidade na qual a interdisciplinaridade com alunos de faixas etárias diferentes e de experiências diversas pode possibilitar uma forma coletiva de inovação e apropriação do conhecimento.

Constatou-se que, em torno de 1995, em função do reduzido número de alunos do campo, as escolas isoladas multisseriadas do município foram nucleadas, o que conduziu a maioria a funcionar até 2010 como seriadas. Entretanto, o contínuo declínio dos discentes no período resultou novamente na necessidade do retorno à implementação das classes multisseriadas na maioria das escolas dos anos iniciais do ensino fundamental, em 2011. A escola EMEF Major Tancredo Penna de Moraes é um exemplo do processo de nucleação de 8 escolas isoladas. Apesar da permanência por 16 anos na seriação, retornou a multisseriação, contando atualmente com 118 alunos.

Apesar da constante redução e reestruturação, o município conta atualmente com 9 escolas do campo e 1365 alunos, representando aproximadamente $20 \%$ do total de Escolas de Ensino Fundamental do município. Portanto, são necessários maiores investimentos e atenção das políticas públicas, com enfoque na formação dos professores tanto em nível de graduação como em formação continuada para implementação de metodologias; procedimentos e técnicas de ensino que busquem a apropriação do conhecimento; redução da carga docente; adequação do conteúdo pedagógico à realidade do campo; e melhoria da estrutura física das escolas, a fim de que continuem sendo desafios constantes para as escolas multisseriadas atender de modo eficaz e inovador à comunidade do campo do município.

Constata-se que as escolas do campo precisam construir uma nova proposta educativa organizada em multisseriação, que leve em consideração os aspectos como: necessidade de investigar as diferentes formas de organização do trabalho pedagógico realizada em turmas diferenciadas por idade e aprendizagens, reformulação da proposta político pedagógica das instituições e do currículo, e políticas públicas que busquem a qualidade e as retirem do anonimato.

Vê-se o trabalho em classes multisseriadas como um desafio. A vantagem nessa maneira de organização do ensino é que o educador pode mediar a inter-relação entre as diferentes faixas etárias e de conhecimentos, tornando o fazer pedagógico mais dialógico, fortalecendo o respeito pelo outro, a valorização das diversidades e o entendimento de que é preciso partir da unidade para o todo. A desvantagem é que o professor tem que estar aberto às mudanças, buscando novas metodologias de trabalho, além de ter que construir diversos planejamentos para atender as necessidades de cada particularidade dos alunos. Isso, muitas vezes, tornase impraticável, uma vez que o professor possui uma carga horária excessiva, não sendo disponibilizado tempo para planejamento e trocas com colegas.

Exercer o papel, enquanto educador da escola do campo, vai além de ensinar os alunos, pois se entende que seja necessário, a partir dos trabalhos na escola, na família e na comunidade escolar, fazer a diferença, respeitando a existência de tempos e modos diversos de ser, viver e produzir.

Nesse sentido, essa prospecção resultou de dados preliminares do estudo que se está

Geografia Ensino \& Pesquisa, v. 17, n.2 p. 129-146, maio/ago. 2013

Escola do campo multisseriada: experiência docente docente, como meio de investigação de novas possibilidades de superação dos entraves e dos desafios enfrentados no ensino multisseriado. 


\section{Referências bibliográficas}

ARROYO, Miguel Gonzalez; CALDART, Roseli Salete; MOLINA, Mônica Castagna, (organizadores). Por uma Educação do Campo, Petrópolis, RJ: Vozes, 2011.

ANTONIO, Clésio Acilino; LUCINI, Marizete. Ensinar e aprender na educação do campo: processos históricos e pedagógicos em relação. Cad. CEDES [online]. 2007, vol.27, n.72, pp. 177-195. ISSN 0101-3262.

BARROS, Oscar Ferreira; HAGE, Salomão Mufarrej. Panorama estatístico e aspectos legais das políticas de nucleação e transporte escolar: Reflexões sobre a extinção das escolas multisseriadas e a sua permanência nas comunidades do campo. UFPB, João Pessoa/ PB, jun/2011.

BERRY, Chris. Achievement effects of multigrade and monograde primary schools in the Turks and Caicos Islands. International Journal of Educational Development, v. 21, p. 537-552, 2001.

BRASIL. Instituto Brasileiro de Geografia e Estática. Síntese de Indicadores. Brasília, 2010.

Lei no 9394/96, Lei de Diretrizes e Bases da Educação Nacional, 20 de dezembro de 1996. Brasília, 1996.

CNB/CEB. Diretrizes Operacionais para a Educação Básica nas Escolas do Campo. Resolução nº1, de 3 de abril de 2002.

Decreto $n^{\circ} 7.352$, de 4 de novembro de 2010. Dispões sobre a Política Nacional de Educação do Campo e sobre o Programa Nacional de Educação na Reforma Agrária. Diário Oficial da União, Brasília, 5 nov. 2010. Disponível em: < http:/ /www.planalto. gov.br/ccivil_03/_ato2007-2010/2010/decreto/d7352.htm>.

BONILLA, Maria Helena Silveira; HALMANN, Adriane Lizbehd. Formação de professores do campo e tecnologias digitais: articulações que apontam para outras dinâmicas pedagógicas e potencializam transformações da realidade. Inter-Ação, Goiânia, v. 36, n. 1, p. 285-308, jan./jun. 2011.

CALAZANS, Maria Julieta Costa. Para compreender a educação do estado no meio rural (traços de uma trajetória). In: THERRIEN, Jacques; DAMASCENO, Maria Nobre. (coord.). Educação e escola do campo. Campinas: Papirus, 1993.

CARDOSO, Maria Angélica; JACOMELI, Mara Regina Martins. Considerações sobre as escolas multisseriadas: Estado da arte. Educere Et. Educare - Revista de Educação ISSN 1809-5208, Cascavel, vol. 5, no 9, p. 267-290, jan/jun 2010.

CAVALCANTE, Ludmila Oliveira Holanda - Das políticas ao cotidiano: entraves e possibilidades para a educação do campo alcançar as escolas no rural - Ensaio: aval. pol. públ. Educ., Rio de Janeiro, v. 18, n. 68, p. 549-564, jul./set. 2010.

CHATTOPADHAY, Tamo. School as a site of student social capital: An exploratory study from Brazil. International Journal of Educational Development, Article in press, 2012. journalhomepage:www.elsevier.com/locate/ijedudev.

Geografia Ensino \& Pesquisa, v. 17, n.2 p. 129-146, maio/ago. 2013

Druzian, F.; Meurer, A. C

ISSN 2236-4994 I $\quad 143$ 
COUTINHO, Nivaldo Paixão, ABREU, Waldir Ferreira de. Precariedade e fracasso escolar em turmas multisseriadas da escola São Francisco Xavier no município de Concórdia do Pará. In. I Encontro de Pesquisas e Práticas em Educação do Campo da Paraíba, Centro de Educação/UFPB, João Pessoa/PB, jun., 2011.

D’ AGOSTINI, Adriana; TAFFAREL Celi Zulke; JÚNIOR, Claudio de Lira dos Santos. "Escola Ativa". In: CALDART, Roseli Salete; PEREIRA, Isabel Brasil; ALENTEJANO, Paulo; FRIGOTTO, Gaudêncio, (Orgs.). Dicionário da Educação do Campo. Rio de Janeiro, São Paulo: Escola Politécnica de Saúde Joaquim Venâncio, Expressão Popular, 2012, p. 313 a 324.

FARIAS, Graziela Franceschet; ANTUNES, Helenise Sangoi- Que Duas Professoras Que Atuaram No Ensino Rural Têm Para Nos Contar? Lembranças De Vida, Histórias Sobre Alfabetização E Trajetórias Pessoais E Profissionais- Poíesis Pedagógica - V.8, N.1 jan./jun. 2010; pp.64-92

FAGUNDES, José; MARTINI, Adair Cesar - Políticas Educacionais: da escola multisseriada à escola nucleada - Olhar de Professor. Ponta Grossa, 6(1): p. 99-118, 2003.

GARNICA, Antonio Vicente Marafioti. Escolas, professores e caipiras: exercício para um descentramento histórico. Educ. Pesqui. [online]. 2005, vol.31, n.1, pp. 121-136. ISSN 15179702.

GARNICA, Antonio Vicente Marafioti. Memórias de uma Escola Isolada Rural: estudo de um Livro de Visitas (1928-1948). Educ. Soc. [online]. 2011, vol.32, n.114, pp. 69-86. ISSN 0101-7330.

GATTI, Bernadete Angelina; DAVIS, Cláudia. Questões sobre o desempenho de alunos de escolas rurais no nordeste e seu contexto sociocultural. In: THERRIEN, Jacques; DAMASCENO, Maria Nobre (Coords.). Educação e escola no campo. Campinas: Papirus, p. 137-173, 1993.

HAGE, Salomão Mufarrej. Por uma escola do campo de qualidade social: transgredindo o paradigma (multi)seriado de ensino. Brasília, v. 24, n. 85, p. 97-113, abr/ 2011.

HARGREAVES, Eleanore. Assessment for learning in the multigrade classroom. International Journal of Educational Development, v. 21, p. 553-560, 2001.

LITTLE, Angela W. Multigrade teaching: towards an international research and policy agenda. International Journal of Educational Development, 21, 481-497, 2001.

MACHADO, Dionéia Lang; KNORST, Patrícia Andréa Rauber - A gestão democrática presente na escola do campo: o caso da Escola de Ensino Fundamental Linha Biguá - SC Unoesc \& Ciência - ACHS, Joaçaba, v. 1, n. 2, p. 111-120, jul./dez. 2010

MARSCHNER, Walter. Lutando e ressignificando o rural em campo: notas epistemológicas. Interações (Campo Grande) [online]. 2011, vol.12, n.1, pp. 41-52. ISSN 1518-7012.

Geografia Ensino \& Pesquisa, v. 17, n.2 p. $129-146$, maio/ago. 2013

Escola do campo multisseriada: experiência docente
MATEDDI, Joelma Sani; MORETO, Charles. Experiências de Educação no meio rural nos municípios de Itarana, Itaguaçu e São Roque do Canaã, na Microregião Centralserrana do Espírito Santo - Instituto Federal do Espírito Santo- IFES, Vitória-ES, [online], nov. 2011.

MATOS, Kelma Socorro Alves Lopes de; WIZNIEWSKY Carmen Rejane Flores, et al. (organizadores). Experiências e Diálogos em Educação do Campo. Fortaleza: Edições 
UFC, 2010.

MOLINA, Mônica Castagna; FREITAS, Helena Célia de Abreu. Avanços e desafios na construção da Educação do Campo (UnB). Revista Em Aberto, Brasília, v. 24, n. 85, p. 17$34, \mathrm{abr} / 2011$.

MOURA, Edinara Alves de. Lugar, Saber Social E Educação No Campo: O Caso Da Escola Municipal De Ensino Fundamental José Paim De Oliveira - Distrito De São Valentim, Santa Maria, RS- Dissertação de Mestrado apresentada a Universidade Federal de Santa Maria-2009

ROCHA, Maria Isabel Antunes; HAGE, Salomão Mufarrej-Escola de Direito: Reinventando a escola multisseriadas - Belo Horizonte : Autêntica Editora, 2010. - (Coleção Caminhos da Educação do Campo ; 2)

ROTTA, Mariza; ONOFRE, Sideney Becker - Perfil da educação do campo: na escola do São Francisco do Bandeira no Município de Dois Vizinhos- PR - Educação, Porto Alegre, v. 33, n. 1, p. $75-84$, jan./abr. 2010

SANTA MARIA. Projeto Político Pedagógico da EMEF Major Tancredo. Santa Maria, 2011.

SPIRONELLO, Rosangela; BEZZI, Meri Lourdes. Adequação do ensino de Geografia a realidade rural: um estudo junto as escolas-núcleo do município de Santa Maria - RS. Revista Gegrafia: Ensino \& Pesquisa, Santa Maria, v.11, n.1, jul., p.51-56, 2001.

TAFFAREL, Celi Nelza Zülke, JÚNIOR, Cláudio de Lira Santos, ESCOBAR, Michelli Ortega (org.); coordenação Adriana D’Agostini, Erika Suruagy Assis de Figueiredo, Mauro Titton. Cadernos didáticos sobre educação no campo. - Salvador/BA, EDITORA Universidade Federal da Bahia/UFBA, 2010.

TEIXEIRA, Edival Sebastião; BERNARTT, Maria de Lourdes and TRINDADE, Glademir Alves. Estudos sobre Pedagogia da Alternância no Brasil: revisão de literatura e perspectivas para a pesquisa. Educ. Pesqui. [online]. 2008, vol.34, n.2, pp. 227-242. ISSN 1517-9702.

VENDRAMINI, Célia Regina. Educação e trabalho: reflexões em torno dos movimentos sociais do campo. Cad. CEDES [online]. 2007, vol.27, n.72, pp. 121-135. ISSN 0101-3262.

WERLE, Flávia Obino Corrêa; BRITTO, Lenir Marina Trindade de Sá and NIENOV, Gisele. Escola Normal Rural e seu impresso estudantil. Educ. rev. [online]. 2007, n.45, pp. 81-105. ISSN 0102-4698.

Geografia Ensino \& Pesquisa, v. 17, n.2 p. 129-146, maio/ago. 2013 


\section{Correspondência:}

Ane Carine Meurer - Rua Cristal 430. Jardim Santa Lúcia Bairro - Camobi. Santa Maria. Cep. $97110-762$

E-mail: acmeurer@terra.com.br

Recebido em 20 de agosto de 2012.

Revisado pelo autor em 02 janeiro de 2013.

Aceito para publicação em 12 de setembro de 2013. 